\title{
Jakarta Post Newspaper to Teach Reading Through GIST (Generating Interaction Between Scemata and Text) Strategy
}

\author{
Nuri Ati Ningsih \\ Universitas PGRI Madiun \\ Madiun, Indonesia \\ nuribasir.nb@gmail.com
}

\begin{abstract}
This article has aim to describe the use of the Jakarta Post newspaper through GIST strategy to teach reading subject and to find not only some weaknesses but also some strengths of using Jakarta Post through GIST in the process of teaching reading. This research is descriptive qualitative method. It is conducted for advance level at English Department of UNIPMA. The research data are collected by doing observation, interview and documentation. The research data are analyzed through three techniques. They involve data reduction, displaying data, and verification. The results show that (1) teaching reading by using Jakarta Post newspaper through GIST strategy are conducted by the lecture in three step; before reading activities, while reading activities, and after reading activities. (2) The weaknesses are; (a) it's time consuming for preparing the appropriate material, and (b) it needs hard effort and higher thinking skill to create an interesting material. Although it seems categorized into a traditional materials, but it has many positive contributions in the process of teaching reading. (3) The strengths of using Jakarta Post and GIST in reading class involve: (a) it increases the students' enthusiasm, (b) it provides joyful reading process, and (c) it develops the student's vocabulary mastery.
\end{abstract}

Keywords-Jakarta Post, newspaper, reading, teaching Strategy, GIST

\section{INTRODUCTION}

Most of the students of English Department still get difficulties in understanding the content of the text. They feel that they have read the words but in fact, they don't know what the text mean. It is real. Then, it becomes the big problem because reading is as a one of fundamental skill in learning process. To be able to develop the students' reading skill, a language teacher needs to apply not only the suitable method but also relevant media. Newspaper is a kind of media almost certainly used by a language teacher to teach reading. It is not a new one but it has a good effect on the process of teaching reading. In 1983, ANPA Foundation published that newspaper is an effective tool to teach reading. This foundation also provides a brief introduction to the newspaper in education concept. However, bringing newspaper in classroom activities needs special preparation in order not to consume much time and make students bored. It does not only to motivate the students but also to encourage them to be better readers.

Many researches have been done and the results show the effectiveness of using newspaper in classroom reading activities. Mittal [1] proposes that there are numerous activities that can be done with newspaper for effective English teaching. Nuttal [2] also states that English newspapers are not expensive, published in daily basis and readily obtainable not only in the form of printed text but also on line. Thus, the use of newspapers helps the students increasing both the students' vocabulary and reading habit. Relating to the use of newspaper in reading class, the English teachers have to be able to select some articles stated in and relate them with the learning outcome will be achieved. Jakarta Post will be used in this research. It is because Jakarta Post as one of the few Indonesian English-Language dailies newspaper. Then, it is supposed that the reader of this newspaper are the foreigners and educated Indonesian.

The objectives of this article are to describe the use of the Jakarta Post newspaper in classroom reading activities conducted by using GIST strategy in advance level and to find not only some weaknesses but also some strengths of using Jakarta Post in the process of teaching reading throwing GIST strategy.

Reading for comprehension is the primary purpose for reading (through this is sometimes overlooked when students are asked to read overly the difficult texts); raising student awareness of main idea in a text exploring the organization of the text are essentials for good comprehension [3]. Patel and Jain [4] classifies the process of reading activities into 3 stages. Those are;

(1) Recognition Stage

The students simply recognize the graphic of the phonological items.

(2) Structuring Stage

The students see the syntactic relationship of the items and understand the structural meaning of the syntactical units.

(3) Interpretation Stage

The students' comprehension of a word, a phrase, or a sentence in the overall context of the discard. 
Comprehension is the highest one. Raising the students' comprehension can be done by developing the students' metacognition. Metacognition will help the students to know how they think and learn. They become truly aware of their learning. Students will become active and purposeful. To achieve it, the students must learn to (1) explain the purpose they are reading, (2) catch the information from the texts, and (3) relate the information with their background of knowledge. By applying these, critical reading process will be developed.

Newspaper can be used as a valuable tool for the English teachers to teach reading. Singatullova, et.al [5] proposes that newspaper articles plays an effective role in learning a foreign language. It does not only reflect the speech activities but also demonstrate the culture of the native speaker. It is also containing information about social life of the learners motivate them to learn, to improve the level of knowledge, to acquire knowledge about the culture of the nation, and to develop skills for understanding. These characteristics will support the teaching process as outside the classroom activities. Nuttal [2] says newspapers contain a wide variety of text type. Therefore, they are classified as natural source of written language then increasingly become very important for the learners to increase their proficiency in foreign language. Because of its valuable characteristic, newspapers will become an authentic material for teaching reading. It will convey many benefit when this material delivered through suitable teaching strategy. Harrel [6] argues that GIST is a suitable teaching strategy can be used for supporting comprehension of informational text. In detail International Reading Association (2011), dealing with GIST strategy, designed worksheet of reading by involving the $5 \mathrm{~W}$ 's (Who, where, when, why what), and a final prediction to get detail information in it.

Relating to theories above, the teacher should be able to combine valuable teaching materials and teaching strategy to achieve the learning outcome favorably.

\section{METHOD}

This research is conducted by applying a descriptive qualitative method. The sample of this research is the first semester students of English Department at Universitas PGRI Madiun. Then, purposive sampling was chosen to select the sample or respondent. They are the lecture of reading class and the first semester students of English Department. The instrument used were checklist of observation, interview guided, teaching devices, and some pictures related to the activities. The research data are collected through observation, interview, and documentation. The obtained data, then, were analyzed through three techniques. Those are data reduction. Displaying data, conclusion and verification [7]. Data reduction is done to select the real data needed gotten from observation, interview and documentation. Meanwhile, displaying data dealing with the way how the researcher presents the main data. Since it is descriptive, it is presented in the form of description. After presenting the data, the researchers make conclusion based on the finding.

\section{RESULT AND DISCUSSION}

This section presents the result of research collected through class observation and interview. Observation was conducted by participant observation. The position of the researcher, in this case, as a part of lectures in reading subject. Because of it, the researcher knows well the situation and the ability of the students in comprehending the text. Almost all of the students get difficulties in understanding the content of the text in every meeting. It can be found in structuring stage and interpreting stage. In structuring stage, most of the students still get the problem in recognizing the sentence pattern. Some of them don't have abilities in differentiate active and passive sentences. Moreover in interpreting stage, most of them don't have sense to interpret the meaning of words. They don't have much knowledge about the existence of various meaning within the same word. They still face the problem in catching the meaning. For instance: the word which has more than one meaning. Such as, the word since which means sejak. Another difficulties are about identifying the words. They are less of knowledge to determine whether the words here as phrase or not. They also get trouble in determining noun, adjective, adverb and verb. Those description, then supported by the following quotation;

Researcher : "What is the specific problem do you get in reading the text?"

Student : "My vocabulary mam."

Researcher : "What is your solution to know the meaning of some difficult words stated in the text."

Students : "I try to find it in my dictionary mam."

Researcher : "After finding the meaning from dictionary, did you still get difficulties."

Student : "yes, of course mam......Sometimes, the meaning of words are not suitable with the context."

Based on the data above, it can be said that the big problem found in reading class is about finding the meaning of the certain words, specific words and phrases. These problems, then, will influence the students' ability in understanding the sentence and the content of the text. Finally, they will fail in getting the context. So, to overcome those conditions, the researcher then decided to look for the interested material and suitable teaching strategy in order to the class activities run well and the learning outcome can be achieved.

Researcher : 'Knowing your students' difficulties, what is your efforts?"

Lecture : "We try to find out a familiar text and comfortable teaching strategy to make the students enjoy and interested in reading class."

Researcher : "Why do you choose Jakarta Post and GIST as your teaching strategy?"

Lecture : "Jakarta Post is easy to be gotten in our campus, even free in charge. Just making coordination with campus library, we will get it soon. Besides, there are so many topics stated in related with our real life so it will 
make the students enjoy and interested knowing a new vocabulary related with their daily."

Jakarta Post newspaper then selected as an authentic material for supporting the reading class. Some considerations in choosing this paper are; (1) it is easy and cheap to get it around, (2) it has a lot of information which make them to be much more familiar than course books, (3) it also consist of different kind of text stated in such as report, advertisement, narratives, letters and also stories, and (4) the text stated in this paper written based on real life sources and have controversial issues. To provide good material in class, some considerations must be taken in choosing the text. It is related with the following data.

Researcher : "What is your considerations in selecting the text from newspaper?"

Lecture : " "in order to be up to date material, so many indicators used to choose them and it need so long process, such as (1) determining the purpose of reading, goal of teaching and level of the students, (2) choosing content/ material, (3) types of the text, (4) designing classroom activities and task."

Turning newspaper to be comfortable reading materials needs some steps done by the lecture. They involve (1) setting reading goal, (2) planning how to attain goals, (3) finding a more interesting text to read on the same topic, (3) reflecting on relevance of text content to future learning, (4) planning reading time, (5) checking if text is suitable to reading level, (6) giving up reading a text, and (7) Subject nominated strategies- (a) ensuring important points are not missed by taking notes of text content, (b) evaluating reading speed [8]. By doing those steps, we will get an interesting material, but it needs a long time to do. Selecting the text are not an easy ways. Nuttal [2] says that to be goal oriented, text should has suitability of content, exploitability, and readability. Among three, suitability is the most important one. Suitability means that the text should make the students interested and motivated and relevant to their needs. Exploitability refers to how the text can be used to develop the students' competencies as a readers. Readability tends to the amount of new vocabulary and any new grammatical form [9]. To do so, it needs high order thinking skill and much more time.

The next step is designing the classroom activities based on GIST strategy.

Lecture : "Why do you choose GIST to support newspaper?"

Researcher : "GIST and newspapers are in tune. Newspaper convey so many text types relevant with our daily life even our spectacular issues. Then, by GIST, lecture can explore the content of the text and the students' competence as much as possible based on its characteristic. GIST also help the students use their previous knowledge and experience to predict the content of the text and support their reading activities. So, it is well-matched."
The activities of GIST are designed into some steps (1) identify type of text (2) make group of students consist of upper and lower ability (3) demonstrate the strategy by providing $5 \mathrm{~W}$ 's and $\mathrm{H}$ in group or individually (4) ask the students write the "GIST" in 20 words (5) discuss the summary of the text (6) read and compose the summary, (7) read and compare the summary and (8) assess students' progress and understanding [10]. Combining both material and teaching strategy needs hard effort to reach the goal. This situation creates extremely time consuming although done out of the classroom activities.

The result of observation shows that after all the instructional cue devices are ready, the lecture brings it to conduct the reading class in classroom activities. The process of teaching reading by using Jakarta Post newspaper and GIST were done as the three steps, they are before reading activities, while reading activities, and after reading activities.

(1) Before Reading Activities

This activity has aim to help the students understand the kind of the text they will read and the overall meaning of the text. Following are some activities suitable to be applied in this step. They involve activating students' prior knowledge, drawing the students' experience related to the text, developing the students' motivation and interest, and asking the students to predict and guess the meaning of some essential vocabulary to support their understanding.

Some questions often used by the lecture in this step are: can you tell what articles will be about from the picture?, what do you already know about this?, etc.

(2) While Reading Activities

In this step, the activities are focused on the microskill of reading as the elements of teaching reading, such as skimming, reading for the gist, using prediction skill, reading for the main ideas, reading in detail, scanning for specific information, using reference skill, and inferring the meaning of unfamiliar words. This step is the most important one cause it is the most active among the three steps. Babaiba [11] explains that the aims of this step are:

a. Students understanding the writers' purpose

b. Helping reading comprehension of the text

c. Helping students to use their inferring and judging abilities

d. Remembering the students of the vocabulary important

e. Developing the students' linguistic and socio linguistic competence

f. Learning generalization

g. Reading consciously

h. Skimming

i. Scanning

Rahul [12] promotes some activities applied by the lectures in using Newspaper in reading classroom are;

a. Daily's reading words from Newspaper 
b. Reading aloud any particular news in the classroom one by one

c. Writing any given news just by changing tense, meaning or omitting particular word.

d. Asking students to read any particular news and reproduce it verbally and then write it in your own way

e. Group discussion on current issues

Some activities above are combined well in GIST strategy into some of learning steps by using Jakarta Post newspapers as an authentic materials in classroom reading activities.

The main activities are running into some steps (1) grouping the students consist of a strong English speaker and reader, then, hand out the worksheet (2) demonstrating the strategy by giving some instructions related to $5 \mathrm{~W}$ 's and $\mathrm{H}$ given to individual or in group (3) asking the students write the new vocabulary and "GIST" of the article/ text in 20 words (5) discussing the summary of the text (6) reading and summarizing paragraph by paragraph (7) reading and comparing the summary and (8) assessing the students' progress and understanding.

Various activities above are constructed by the lectures based on the goal of teaching and the level of the students. Combining teaching strategy, reading strategy and newspaper as a text, established the joyful reading process. It is supported by the result of interview below:

Researcher : "What is your opinion about the
material taken from Jakarta Post newspaper?"
Student : "In my opinion, it is a good way. I
fell enjoy and relax in attending the class."
Researcher : "Could you give me the reason
about your felling?"
Student "I feel comfort in class because I
have feeling familiar with the text. So, I can predict
the meaning of some unfamiliar words stated in the
text easily. It makes us proud and happy."

The data above indicate that the students felt very enthusiastic in attending the reading class. The material facilitated the students in rising vocabulary mastery. In addition, it is also hard to be realized because it needs long time to prepare the materials into appropriate one. Researcher : "Do you find some problems in
preparing both?"

Lecture : "Of course, we need not only much time and energy but also high thinking skill to organize them into good material in order to the students are interested and encouraged to follow the class."

\section{(3) After Reading Activities}

The aim of this step is to stimulate the students to give their reaction about the text in a personal way.

a. Giving opinion about the text b. Telling the content of the text from another perspective

c. Comprehending the text in another language form.

Some activities above are employed by the lecture to examine the students' understanding. The result of this step will be used to evaluate the process and to find the new strategies for the next performance.

\section{CONCLUSION}

Teaching reading by using Jakarta Post are conducted by the lecture in three step; before reading activities, while reading activities and after reading activities. Each of them has different purposes. First, before reading activities aim helping the students understand the kind of the text and meaning of the text. Second, while reading activities are the most important one. It consist of some various activities conducted in GIST strategy which support the students in achieving the goal based on the micro skill of reading. Lastly, after reading activities are to investigate the students' understanding. In this case, the position of the lecture as a facilitator and conductor. $\mathrm{He} / \mathrm{she}$ facilitate the class with the suitable reading strategy and an interesting material. As a conductor, he/she conducted the students by using some instructions to get deep understanding and develop students' motivation.

The weaknesses are; (1) it consumes much time for preparing the appropriate material, and (2) it needs hard effort and higher thinking skill to create an interesting material. Although it seems categorized into a traditional materials, but it has many positive contributions in the process of teaching reading. The strengths of using Jakarta Post and GIST in reading class involve: (1) it increases the students' enthusiasm, (2) it provides joyful reading process, and (3) it raising the student's vocabulary mastery.

\section{REFERENCES}

[1] R. Mittal, Role of Newspaper in English Learning Language. International Journal of Research(IJR) Vol. 1. Issue-6. Jully, 2014.

[2] C. Nuttal, Teaching Reading Sills in A Foreign Language (New Edition) Heineman, 1996.

[3] J. C. Richarcds and R. Willy A (Eds), Methodology in Language Teaching: An Anthology of Current Practice, New York: Cambridge University, 2002

[4] M.F. Patel, and P. M. Jain, English Language Teaching. Jaipur: Sunrise Publisers \& Distributors, 2008.

[5] A. Singatullova, L. Sakaeva and G. Ismagilova, Reading Newspaper Articles as a Motivation Tool for Students With NonLinguistic Major.Journal of History Culture and Art Research, Vol. 6 No.5, 2017.

[6] A. L. Harrel, Fifty Strategies for Teaching English Language Learners. New Jersey: Prantice-Hall Inc., 2000.

[7] Miles and Hubberman, Qualitative Data Analysis. London. Sage, 1994

[8] L. DoHuy, J. Hull and S. Tepsuriwong, Effect of Extensive Reading on Students' Perception of Reading Ability and Use of Reading Strategies. rEFLections Journal of Language Education. Volume 8. King Mongkut's University of Technology Thonburi Thailand, 2006.

[9] S. A. Barado, The Use of Authentic Materials in The Teaching of Reading. The Reading Matrix. Vol.6 No 2 September, 2006.

[10] A. N. Ningsih and A. Kurniawan, Teaching Reading By Using GIST Strategy Viewed From The students's Cognitive Aspect On The Extensive Level Of English Department Students IKIP PGRI Madiun. English Teaching Journal, Vol.3 No.2 . Desember, 2015. 
[11] W. Babaiba, Reading Comprehension Difficulties Among EFL Learner: The Case Of Third-Year Leraners at Nehali Mohamed Secodary Scool. University of Tlemcen, 2015.

[12] S. Rahul, Role of Newspapers in Learning English Language: A Linguistic Study. International Journal of English Language, Literature and Translation Studies (UELR). Vol.3, 2016. 